\title{
A Comparison of Partial and Complete Paired Comparisons in Sociometric Measurement of Preschool Groups
}

\author{
Allan S. Cohen and Elizabeth Van Tassel \\ Purdue University
}

Low test-retest reliabilities over periods from ten days to five months have been obtained on a partial-rank order sociometric, the PSI, of preschoolage children's peer preferences. These results have been interpreted to mean that preschool-age children do not have stable and enduring friendships with their peers. An alternative possibility is that the reliabilities of partially ranked data are so low as to obscure the existence of stable individual friendships in this age group. A full-rank order sociometric instrument, the PCST, utilizing color photographs of the children in a preschool group as aids in eliciting friendship choices from the children, was developed and tested on a group of threeyear-olds and a group of four-year-olds. The sociometric measurements from both the PSI and the PCST were most reliable for the four-year-old group. Correlations between the PSI and the PCST, when corrected for attenuation, revealed that the two measures were probably assessing the same peer choice behavior, although the PCST was markedly superior in reliability. Administration time for the PCST was higher but substantially less than for previous paired-comparisons procedures.

Measurements of preference choices which are not strongly held tend to be less reliable than measurements of preferences which are clearly defined or well identified in the individual. The reliability of the resulting data is likely to decrease even further when such measurements

APPLIED PSYCHOLOGICAL MEASUREMENT

Vol. 2, No. 1 Winter 1978 pp. 31-40

(c) Copyright 1978 West Publishing Co. are made using procedures which do not fully rank the set of responses given by a person. Unfortunately, when methods such as the technique of paired-comparisons (Thurstone, 1927) are used to fully rank responses, the cost of data collection often rises dramatically. Since this problem is an especially relevant issue to researchers of the development of children, the present study was designed to compare both full- and partial-rank-ordering procedures of measurement within the context of preschool peer preferences. Specifically, it was intended to determine if increased reliability could be obtained from a full-ranking procedure without substantially affecting the ease or cost of obtaining the measurements.

Sociometric measurement of peer preferences has been used for more than four decades as a means of identifying and studying social interactions among preschool children (Koch, 1933; Lippit, 1941; McCandless \& Marshall, 1957; Moore \& Updegraff, 1964). Test-retest correlations on data obtained with existing sociometric instruments used with preschool groups, however, have been only moderate when assessing individual friendships. Coefficients from these studies have ranged from .43 to .85 over a tenday interval (McCandless \& Marshall, 1957), from .52 to .78 over a two-week interval (Moore \& Updegraff, 1964) and as low as .32 over a fivemonth period (Hartup, Glazer, \& Charlesworth, 
1967). Furthermore, studies comparing sociometric results with specific social behaviors observed during peer interactions have yielded low relationships among these two sets of variables. This evidence has led researchers to the interpretation that, in this particular age range, social behaviors are not very important in the formation and maintenance of individual friendships (Hartup, 1970). Yet, it is quite possible that these findings reflect measurement problems rather than poor relationships.

In fact, strong regularities have been found in both the quality and quantity of peer interaction behaviors among preschool-age children (Blurton-Jones, 1972; McGrew, 1972; Smith \& Connolly, 1972). This would suggest that, in spite of situational and temporal influences which may affect preschool friendships, social skills are both evident and stable across similar situational contexts throughout the preschool years. In view of the relatively low reliability coefficients noted above, particularly over extended periods of time, it may be that failure to demonstrate a strong relationship between friends (or peer preferences) and social behaviors is due less to the lack of such a relationship than to the poor quality of data obtained from the sociometric measures used.

In most of the studies on peer preferences, the form of sociometric used has been that developed by Moore and Updegraff (1964). Their Picture Sociometric Interview (PSI) combined the use of photographs of the children in the group (McCandless \& Marshall, 1957) with an interview procedure developed by Dunnington (1957). The resulting PSI required the child to make both acceptance and rejection choices for all of the children in his/her group in response to an examiner asking whether he/she liked or disliked playing with the particular child in the photograph. (Play is probably the most commonly used referent situation in preschool sociometric testing.)

One basic problem with the PSI, which stems from its being a partial-rank-ordering technique, is that the responses are not made during a full or even an equal consideration of all of the group members. While each child provides a set of responses of either acceptance or rejection of each of his/her peers in the group (e.g., his/her classroom), he/she is neither specifically required nor constrained to consider each member of the group equally when making his/her choices. Consequently, those children who are not on the extremes of their friendship distribution (i.e., recipients of initial acceptance or rejection choices) are ranked in the middle of the distribution more by default than by specific comparison with each of the other children. When this default ranking, typical of partial-ranking methods, is combined with the basically egocentric orientation of preschool children, it exacerbates the problem of reliability in assessing the individual friendship preferences of the children in the classroom.

A full-ranking procedure was first implemented by Koch (1933) on a preschool-age sample. Using the method of paired comparisons (Thurstone, 1927), Koch required the child to consider each of the children in the classroom on an equal basis, thereby removing the default nature of partial-ranking methods (such as the subsequent PSI). However, Koch's instrument was completely verbal; consequently it was quite difficult for the 17 four-year-old children in her sample. Lippit (1941) used the same procedure and reported that 14 preschool children in her sample required an extremely long time (6 to 12 hours per child) to make their friendship choices.

Despite the considerable administration times reported by Lippit, the paired-comparisons procedure has special appeal; specifically, it provides a fully ranked set of responses from each child in the group. Furthermore, Wytrol and Thompson (1953) reported this method to be more reliable than partial-ranking methods when used on samples of older (sixth grade) children. Although these results were obtained with older subjects, it seems likely that a similar form of sociometric would provide more reliable data than the PSI for preschool groups as well. 
The inclusion of photographs with the pairedcomparisons procedure, as an aid to assist the children in making their peer preference choices quickly, should result in significant reductions in administration times over those reported by Lippit.

The major objective of this study, therefore, was to develop a paired-comparisons form of a sociometric instrument using the photographs of the children in the classroom which would be more reliable than the existing form of the PSI. The investigation also included an examination and comparison of the administration times required for both the paired-comparisons instrument and for the PSI.

\section{Method}

\section{Sociometric Instruments}

Paired-Comparisons Sociometric Test (PCST). The PCST consisted of two looseleaf notebooks; each contained copies of $7.8 \mathrm{~cm} \times 7.8$ $\mathrm{cm}$ color photographs of the head and upper shoulders of each child in the classroom. The order of photographs in each column was determined from a table of random numbers and was the same in both volumes of a PCST set. In the same manner, the order of presentation of each pair was randomly determined. The complete set of pairs shown to any child consisted of all pairs excluding those in which his or her photograph occurred. Using the generalized formula for this number of pairs, $(n-1)(n-2) / 2$, where $n=$ the number of children in the class, it was evident that a large number of pairs could result ( 153 pairs in a class of 19 children and 190 pairs in a class of 21 children). To reduce the length of the task potentially required of the child at a single sitting, the total list of pairs was randomly formed into five shorter and approximately equal length sublists. These sublists were administered one or two at a time to each child on a single day of testing. For a single administration of a PCST, each photograph of a child appeared an equal number of times as the right or left member of a pair across all pairs in which the photograph was used. For the spring testing in the three-year-old class, this order was reversed. (Due to unavoidable circumstances, a third assessment on the four-year-old group was not possible.) Two scores were computed from the responses to the PCST from a single administration: (1) the percentage of times each child selected particular children in his classroom (individual friendships) and (2) the percentage of times each child was selected by other children in the class (peer group social status).

Picture Sociometric Interview (PSI). The PSI used color copies of the same photographs as the PCST. Photographs for a single class were displayed in rows and columns on a single $76 \mathrm{~cm}$ $\times 50.7 \mathrm{~cm}$ white posterboard in the same order that they appeared in the PCST. Scoring was done according to procedures described by Moore and Updegraff (1964). This procedure weights the first responses more heavily; the first four acceptance responses from each child were scored as $8,6,4$, and 3 points, respectively. Similarly, the first four rejection responses were scored $-8,-6,-4$, and -3 points, respectively. The remaining responses (called forced choices) were scored +1 for an acceptance and -1 for a rejection choice. Four scores were computed from the data for a single administration: (1) the responses made by each child to each of the other children in the class (individual friendships); (2) the algebraic sum of the acceptance and rejection scores each child received from his or her classmates (peer group social status); (3) the sum of acceptance scores (peer group acceptance); and (4) the sum of rejection scores (peer group rejection). The acceptance scores for both individual friendships and for peer group acceptance comprise the same data which would be available from a single administration of the McCandless and Marshall (1957) instrument. Scores 1 and 2 are the same as defined by Moore and Updegraff (1964). Hartup et al. (1967) reported scores 3 and 4 in addition to score 2 .

\section{Subjects}

Children in two classrooms of the Purdue 
University Child Development Laboratories were used as subjects in this study. In the threeyear-old classroom the age range at the first testing of the children was 3.1 to 4.0 years; the mean age was 3.57 . Sixteen ( 10 boys and 6 girls) of the 24 children enrolled in the class were present for each of the three administrations of the two sociometric instruments. In the four-year-old classroom the age range at the first testing of the children was 4.1 to 5.0 years; the mean age was 4.69. Eighteen ( 13 boys and 5 girls) of the 21 children enrolled were present for each of two administrations of the sociometric instruments. Only the responses of those children who were present during each of the administrations were analyzed for the present study.

\section{Procedures}

Administration of the tests. PSI testing was begun one month after the two classes had been in session. PCST testing followed completion of the PSI. For all testing children were individually taken from their classrooms by an adult examiner. The referent situation used for both sociometric measures consisted of asking the child with whom he/she would most like to play inside the classroom. The PCST was administered one sublist at a time. In most cases, the children in both classes were willing to work through two sublists at a single sitting; in fact, they expressed great interest in looking at all of the pictures. However, no more than two sublists were given to a child on any single day of testing.
All sublists for a class were completed within 14 days. Three administrations of the sociometric measures were conducted in the three-year-old class: (1) in the fall, one month after class had started; (2) in the winter, three months after the end of the fall testing; and (3) in the spring, one month after the winter testing. For each administration the PSI and PCST measures contained photographs of all children enrolled in the class, even those whose scores were later excluded from the analyses. Two administrations were completed for the four-year-old class: (1) in the fall, one month after their class had started; and (2) in the winter, three months after the completion of the fall testing. Because of time limitations on the use of the children in the fouryear-old classroom, only two administrations were possible for this group.

It is evident from Table 1 that, for some administrations, the loss of information for the PCST was considerable. Because of the loss of information, the results reported in the next section are on less than complete data from all subjects.

Behavioral observation of friendship preferences. Gronlund (1959) has suggested that sociometric measurements be validated by comparing them with the actual or observed friendships which occur in the referent situation. Children were observed, therefore, during their free play times inside their classrooms. Behaviors were recorded on video tapes with a television camera and a video-tape recorder located inside a partially concealed observation booth. These

Table 1

Number and Percent of Subjects for the PSI and Number and Percent of Sublists from the PCST for which Data Were Available for Analyses

\begin{tabular}{|c|c|c|c|c|c|c|c|c|c|c|}
\hline \multirow[b]{4}{*}{ Measure } & \multicolumn{10}{|c|}{ Class } \\
\hline & \multicolumn{6}{|c|}{ Three-Year-0ld } & \multicolumn{4}{|c|}{ Four-Year-0Id } \\
\hline & \multicolumn{2}{|c|}{ Fa11 } & \multicolumn{2}{|c|}{ Winter } & \multicolumn{2}{|c|}{ Spring } & \multicolumn{2}{|c|}{ Fa11 } & \multicolumn{2}{|c|}{ Winter } \\
\hline & $\mathrm{N}$ & $\%$ & $\mathrm{~N}$ & $\%$ & $\mathrm{~N}$ & $\%$ & $\overline{\mathbf{N}}$ & $\%$ & $\overline{\mathrm{N}}$ & $\%$ \\
\hline PSI & 16 & 100 & 16 & 100 & 16 & 100 & 18 & 100 & 18 & 100 \\
\hline PCST & 73.5 & 92 & 52.0 & 65 & 60.0 & 75 & 65.7 & 73 & 80.9 & 80 \\
\hline
\end{tabular}


recordings were made immediately after the winter testing. Each child was videotaped in random order after he or she had been inside the classroom for at least five minutes. Behaviors were videotaped for continuous periods of no more than five minutes.

Four hours and 32 minutes of peer interactions were obtained in the classrooms. This represented an average of eight minutes of taping on each child in the sample. An effort was made to videotape the child's whole body as well as an additional surrounding area of four or five feet in order to note with whom the child was interacting. Exceptions occurred when the target child moved behind toys, other children, furniture, or out of the range of the camera. The view was also obscured by other children moving in front of the target child. No children were taped during the sociometric testing times since removal of any child from the room would have affected the occurrence of natural peer interactions in the room. All recordings of behavior were completed by the end of one week following the final collection of sociometric data for the winter testing period.

Observations were made by the two authors at 15-second intervals from the videotapes on each child. All interactions were defined on the basis of physical proximity to other children (cf. Blurton-Jones, 1972). For an interaction to be possible, the distance between the target child and another child (or children) had to be equal to or less than the target child's arm length. If this distance was observed at the start of the 15second interval, the target child was scored as having an interaction with the other child (or children). Two scores were obtained from these observations: (1) the total number of intervals in which a child was observed interacting with each of the other children (individual friendships) and (2) the total number of intervals in which the child was observed interacting with other children (group social status). Inter-rater agreement (defined as the number of intervals on which both raters agreed divided by the total number of intervals observed) was $99 \%$ for both scores computed over the observed sequences of behavior for eight randomly selected children.

\section{Results}

Test-retest reliability estimates for the PSI and the PCST were computed as correlations between each of the testing periods and within classrooms for the scores described earlier (see Table 2). Total test comparisons (i.e., the total data available from a subject, whether or not this consisted of completion of all items on the PSI or all the pairs on the PCST) indicated that the PCST generally provided more reliable measurements of both group and individual friendships than the PSI. In addition, all possible distinct combinations of $1,2,3$, and 4 sublists on the PCST (when such data were available from a subject) were formed and compared with the total test data from the PCST. The single sublists were each correlated with the total test data from the opposite testing time and the resulting correlations then averaged. Combinations of two sublists were also formed, consisting of all possible distinct sets of two sublists from a single administration. These combinations were then correlated with the total test data from the opposite administration. In each case, the resulting correlations for a set of sublist combinations were averaged.

The values reported in Table 2 are averages, then, of correlations between a total PCST and a sublist combination from the opposite testing time. Fall total test data and winter sublist combinations were correlated and averaged with the correlations between the winter total test data and fall sublist combinations. From these coefficients, it appears that a single PCST sublist provided more reliable information for the measurement of individual friendship choices in nearly every instance than did the PSI. For peer group (i.e., classroom) level information, two or more sublists of the PCST provided more precise information than any of the PSI scores.

The average time taken to complete a single sublist of the PCST (7.36 minutes for three-year- 
Table 2

Test-retest Correlations for PSI and PCST Measures

\begin{tabular}{|c|c|c|c|c|}
\hline \multirow[b]{3}{*}{ Measure } & \multicolumn{4}{|c|}{ Class } \\
\hline & \multicolumn{3}{|c|}{$\begin{array}{c}\text { Three-Year-01d } \\
(\mathrm{N}=16)\end{array}$} & \multirow{2}{*}{$\begin{array}{c}\text { Four-Year-010 } \\
(\mathrm{N}=18) \\
\text { Winter/ } \\
\text { Spring } \\
\end{array}$} \\
\hline & $\begin{array}{l}\text { Fa11/ } \\
\text { Winter }\end{array}$ & $\begin{array}{l}\text { Winter/ } \\
\text { Spring }\end{array}$ & $\begin{array}{l}\text { Fall/ } \\
\text { Spring }\end{array}$ & \\
\hline \multicolumn{5}{|l|}{ PSI } \\
\hline \multicolumn{5}{|l|}{ Individual } \\
\hline Friendships & .10 & .32 & .16 & .26 \\
\hline \multicolumn{5}{|l|}{ Peer Group } \\
\hline Social Status & .16 & .42 & .66 & .81 \\
\hline \multicolumn{5}{|l|}{ Peer Group } \\
\hline Acceptance & .50 & .73 & .76 & .74 \\
\hline \multicolumn{5}{|l|}{ Peer Group } \\
\hline Rejection & .10 & .31 & .44 & .69 \\
\hline \multicolumn{5}{|l|}{ PCST } \\
\hline \multicolumn{5}{|l|}{ Individual } \\
\hline \multicolumn{5}{|l|}{ Friendships } \\
\hline 1 Sublist & .25 & .23 & .21 & .50 \\
\hline 2 Sublists & .35 & .31 & .31 & .65 \\
\hline 3 Sublists & .43 & .39 & .29 & .74 \\
\hline 4 Sublists & .47 & .43 & .33 & .78 \\
\hline 5 Sublists & .50 & .47 & .47 & .80 \\
\hline \multicolumn{5}{|l|}{ Peer Group } \\
\hline Social Status & & & & \\
\hline 1 Sublist & .44 & .58 & .37 & .72 \\
\hline 2 Sublists & .52 & .72 & .44 & .83 \\
\hline 3 Sublists & .57 & .80 & .49 & .87 \\
\hline 4 Sublists & .60 & .84 & .52 & .88 \\
\hline 5 Sublists & .62 & .87 & .53 & .90 \\
\hline
\end{tabular}

olds and 6.14 minutes for four-year-olds) was approximately twice that for a single PSI (3.04 and 3.13 , respectively, in both the three-year-old and four-year-old classes). In all cases, however, the full-length PCST required far less time (between 32.27 and 39.42 minutes for the threeyear-olds and 27.37 and 32.51 minutes for the four-year-olds) than the six to twelve hours reported by Lippit (1941).

Concurrent validity correlations between the PSI and PCST measurements of individual friendship choices were low for the three-yearold class $(.19, .16$, and .16 for fall, winter, and spring, respectively). For the four-year-old class, these correlations were only moderate $(.37$ and .54 for fall and winter, respectively). Correlations between peer group level measurements, however, were moderate to high in most instances for both classes (see Table 3). Since the problems of the reliability of the PSI were a central concern of this study, the correlations for the individual friendships were corrected for attenuation in the PSI only. Resulting coefficients were $.60, .28$, and .40 for the fall, winter, and spring testing times in the three-year-old class and .73 and 1.0 for the fall and winter testings in 
Table 3

Correlations Between PCST and PSI Peer Group Level Scores

\begin{tabular}{lcccc}
\hline & \multicolumn{3}{c}{ Class } \\
\cline { 2 - 5 } & \multicolumn{2}{c}{$\begin{array}{c}\text { Three-Year-01d } \\
(\mathrm{N}=16)\end{array}$} & \multicolumn{2}{c}{$\begin{array}{c}\text { Four-Year-01d } \\
(\mathrm{N}=18)\end{array}$} \\
\cline { 2 - 5 } $\begin{array}{l}\text { Group and } \\
\text { Variable }\end{array}$ & PSI & PSI & PSI & PSI \\
\hline
\end{tabular}

$\mathrm{Fal1}$

\begin{tabular}{|c|c|c|c|c|c|c|}
\hline PSI-Status & .33 & & & .84 & & \\
\hline PSI-Acceptance & .45 & .83 & & .78 & .90 & \\
\hline PSI-Rejection & .10 & .83 & .38 & .46 & .90 & .61 \\
\hline \multicolumn{7}{|l|}{ Winter } \\
\hline PSI-Status & .49 & & & .82 & & \\
\hline PSI-Acceptance & .44 & .60 & & .76 & .87 & \\
\hline PSI-Rejection & .33 & .87 & .12 & .74 & .92 & .62 \\
\hline \multicolumn{7}{|l|}{ Spring } \\
\hline PSI-Status & .75 & & & & & \\
\hline PSI-Acceptance & .46 & .81 & & & & \\
\hline PSI-Rejection & .77 & .86 & .38 & & & \\
\hline
\end{tabular}

the four-year-old class. When these same correlations were also corrected for attenuation in the PCST, the resulting coefficients for individual friendships in the three-year-old class were .85 , .41 , and .58 for the fall, winter, and spring testings, respectively. For the four-year-old class, the values were 1.0 for both the fall and winter .testing times. Although the uncorrected correlations between the PSI and the PCST were low to moderate in both classes for individual friendships, the corrections noted above indicate that much of this may possibly be explained by the low reliability of the PSI data.

Within both classrooms the proportions of time children were observed playing with one or more of their first four friendship choices (four was used since only this number can be identified with a PSI) were compared. In the threeyear-old classroom these proportions were .04 for both the PCST and PSI "best friend" rankings. In the four-year-old classroom, the proportions were .10 and .08 for the PCST and PSI, respectively. No significant differences were found for either comparison. Similar results were obtained for group level comparisons.

\section{Discussion}

The present investigation was designed to develop and test the Paired-Comparisons Sociometric Test (PCST) and to determine whether this kind of assessment methodology provided more reliable information than that obtained from the Picture Sociometric Interview (PSI), a commonly used partial-ranking method for preschool groups. As expected, the results indicated that the PCST was a more reliable assessment procedure than the PSI for both individual friendship choices and peer group social status measurements. Correlations between administrations of the PCST indicated that individual friendship choices among three-year-old children were only moderately reliable over either a three- or four-month period. This contrasted markedly with the high reliability found for individual friendships among the four-year-old children. Similar correlations for the PSI data were much lower and may indicate that the reliability of friendships in both age groups has been underestimated by the partial-ranking procedure.

Comparison of administration times indicated 
that a single PCST sublist required about twice as much time as the full PSI. However, the 15 or 20 minutes required for an average two or three sublist PCST (i.e., a "shortened" version), does not seem to be excessive in view of the higher quality of information obtained over that from the PSI. Although the administration times tended to decrease the longer the group was together (e.g., from fall to winter to spring for the three-year-old group), the meaning of this decrease was not clear from the present study. It may be that age or increased familiarity facilitates children's friendship choice-making at this very young age. Similarly. it may be that children became more familiar with the testing procedures and thereby reduced the amount of time they needed to make their choices.

The information from the PSI and the shortened versions of the PCST were compared for each testing period. In most cases, the shortened versions of the PCST were found to be at least as reliable as the PSI for both peer group social status and for individual friendship measurements. Test-retest reliability correlations of the shortened instruments indicated that a three-sublist PCST was about as reliable as the full five-sublist instrument for the three-year-old group. For investigations concerned with both group and individual friendship measurements on three-year-old samples, therefore, a PCST of at least three sublists would probably provide more and better information than a single PSI. For the four-year-old class, the information from two PCST sublists appeared to be almost as reliable as the information from the fulllength PCST. Therefore, two sublists could probably be used as a shortened version of the PCST on samples of four-year-old children.

Low correlations between the PSI and the PCST individual friendship measurements could be interpreted to mean that the two instruments were not measuring the same behaviors. However, corrections for attenuation in the PSI and in the PSI and the PCST together revealed that the two instruments were probably measuring the same individual friendship choices, al- though with markedly different levels of reliability. The correlation between the group level information from both instruments, however, was moderate to high. Of additional interest were the correlations between PCST and the three PSI peer group scores. These appear to suggest that the three group level scores obtained from the PSI, peer group status, peer group acceptance, and peer group rejection were all correlated with the single PCST peer group social status score. Comparisons among these three PSI scores, however, were similar to results reported earlier (cf. Hartup et al., 1967). The meaning of this was not immediately clear from the results of the present study. It may be that the acceptance and rejection scores from the PSI do not reflect independent aspects of peer group popularity as was initially suggested by Moore and Updegraff (1964). Correlations between these three measures (see Table 3) do not reflect such independence and may indicate that the PSI does not measure two dimensions of the peer popularity variable (i.e., acceptance and rejection).

The proportion of time children were observed interacting with their first four friendship choices was quite small and did not differ between measures in either class. The results are similar to previous findings (Biehler, 1954; Deutsch, 1974). A possible explanation is that the observational data of children's peer interactions are themselves partial-rank-order information and may only incompletely reflect the children's full set of friendship choices. That is, since children tend to play with those children with whom they are most friendly, there is a decreased likelihood that they will be observed playing with their lower choice peers, except under unusual conditions. Nonetheless, it might be argued that extending observation times beyond those reported in the present study would have provided somewhat better information upon which to base comparisons with the sociometric choices. However, similar results for group level data to those of the present study were also reported by Marshall and McCandless (1957) 
based upon approximately four times as much observational data.

The most probable explanation may, in fact, be due to a combination of these two explanations. It is likely that both situational and environmental factors constrained the children's peer interactions causing the observational data to be less like their sociometric choices. For example, the most desired playmate of one child may not reciprocate the same level of friendship but may prefer, instead, to play with another child. The result would be a lowering in the relationship between the child's sociometric choices and his/her actual playmates.

The present full-ranking measure of children's peer preferences has demonstrated an increase in reliability over partial-ranking measures. A possible reason for the large proportion of error variance present in the partial-rank-ordered friendship choices was suggested in the introduction to this paper. That is, preschool-age children themselves may not necessarily be totally aware of their own friendship preferences. Methods such as that of the PSI, which allow the child to give incompletely ranked responses, may be simply failing to take this uncertainty into account.

In fact, Piaget (1955) has suggested that such uncertainty is a reflection of the basically egocentric orientation of the three- and four-yearold child. The egocentric orientation of the child would mean that he or she is less aware of his/her peers than older children would be. Such egocentrism, furthermore, would likely function to lower the reliabilities of peer preference information. Partial-rank-ordered sociometric measures, then, incompletely sample a set of preferences which initially are not well-defined in the child. Requiring the child to consider all his/her peers equally when making such choices on a PCST should not be expected to remove the effects of egocentrism. However, the influence of egocentrism on the reliability of the preference data would likely be minimized.

The measurement problems associated with peer preferences of preschool-age children are not isolated to just that variable. Partial-rankordering measures on these children generally suffer from low reliability, especially when the choices are made on uncertain or ill-defined preferences or judgments. Therefore, use of measurement procedures which provide a fully ranked set of responses would appear to be a useful and legitimate approach to the assessment of such behaviors.

\section{References}

Biehler, R. F. Companion choice behavior in the kindergarten. Child Development, 1954, 25, 45-50.

Blurton-Jones, N. G. Categories of child-child interaction. In N. Blurton-Jones (Ed.), Ethological studies of child behavior. Cambridge: Cambridge University Press, 1972.

Deutsch, F. Observational and sociometric measures of peer popularity and their relation to egocentric communication in female preschoolers. Developmental Psychology, 1974, 10, 745-757.

Dunnington, M. J. Behavioral differences of sociometric status groups in a nursery school. Child Development, 1957, 28, 103-111.

Gronlund, N. E. Sociometry in the classroom. New York: John Wiley \& Sons, Inc., 1959.

Hartup, W. W. Peer interaction and social organization. In P. H. Mussen (Ed.), Carmichael's manual of child psychology (Vol. 2). New York: John Wiley \& Sons, Inc., 1970, 361-456.

Hartup, W. W., Glazer, J. A., \& Charlesworth, R. Peer reinforcement and sociometric status. Child Development, 1967, 38, 1017-1024.

Koch, H. L. Popularity in preschool children. Child Development, 1933, 4, 164-175.

Lippit, R. Popularity among preschool children. Child Development, 1941, 11, 305-332.

Marshall, H.R., \& McCandless, B. R. A. study in prediction of social behavior of preschool children. Child Development. 1957, 28, 149-159.

McCandless, B. R., \& Marshall, H. R. A picturesociometric technique for preschool children and its relation to teacher judgments of friendship. Child Development, 1957, 28, 139-149.

McGrew, W. C. An ethological study of children's behavior. New York: Academic Press, 1972.

Moore, S. G., \& Updegraff, R. Sociometric status of preschool children related to age, sex, nurturancegiving and dependency. Child Development, 1964, 35, 519-524.

Piaget, J. The language and thoughts of the child. New York: World, 1955. 
Smith, P. K., \& Connolly, K. Patterns of play and social interaction in preschool children. In N. Blurton-Jones (Ed.), Ethological studies of child behavior. Cambridge: Cambridge University Press, 1972.

Thurstone, L. L. An experimental study of nationality preferences. Journal of General Psychology, 1927, $1,405-425$.

Wytrol, S. L., \& Thompson, G. G. A critical review of the stability of social acceptability scores obtained with the partial-rank-order and the pairedcomparison scales. Genetic Psychology Monographs, 1953, 48, 221-260.

\section{Acknowledgment}

This research was conducted under the support of the Agricultural Experiment Station. Purdue University. journal paper number 6481 .

\section{Author's Address}

Allan S. Cohen, Elizabeth Van Tassel, Department of Child Development and Family Studies, Purdue University, West Lafayette, IN 47907. 